\title{
$R 53$
}

\section{FISCAL YEAR 1998 YEAR-END REPORT}

for the November 1997 to October 1998 Period

\section{CHARACTERIZATION OF PIPES USING ELECTRET ION CHAMBERS}

\section{Principal Investigator:}

M.A. Ebadian, Ph.D.

Florida International University

Collaborators:

J.F. Boudreaux

S.F. Dua

Prepared for:

U.S. Department of Energy Office of Environmental Management Office of Science and Technology

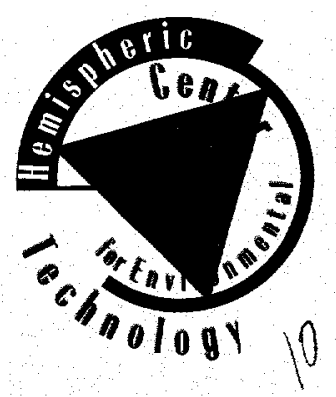




\section{DISCLAIMER}

This report was prepared as an account of work sponsored by an agency of the United States government. Neither the United States government nor any agency thereof, nor any of their employees, nor any of its contractors, subcontractors, nor their employees makes any warranty, express or implied, or assumes any legal liability or responsibility for the accuracy, completeness, or usefulness of any information, apparatus, product, or process disclosed, or represents that its use would not infringe upon privately owned rights. Reference herein to any specific commercial product, process, or service by trade name, trademark, manufacturer, or otherwise does not necessarily constitute or imply its endorsement, recommendation, or favoring by the United States government or any agency thereof. The views and opinions of authors expressed herein do not necessarily state or reflect those of the United States government or any agency thereof. 


\section{DISCLAIMER}

Portions of this document may be illegible in electronic image products. Images are produced from the best available original document. 


\section{CHARACTERIZATION OF PIPES USING ELCTRET ION CHAMBERS}

\section{Principal Investigator}

M.A. Ebadian, Ph.D.

Hemispheric Center for Environmental Technology

Florida International University

Miami, FL 33174

\section{Florida International University Collaborators:}

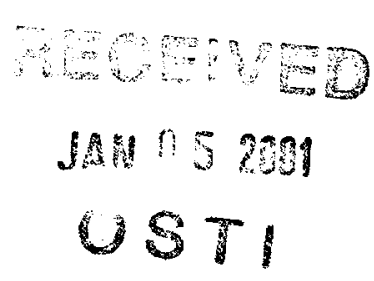

\section{J.F. Boudreaux}

S.K. Dua

Hemispheric Center for Environmental Technology

Florida International University

Miami, FL 33174

January 1999

\section{Prepared for}

U.S. Department of Energy

Office of Environmental Management

Office of Science and Technology

U.S. Department of Energy

Under Grant No. DE-FG-01-95EW55094 


\section{ACKNOWLEDGMENTS}

This report is based on work supported by the U.S. Department of Energy, Office of Environmental Management, Office of Science and Technology's Deactivation and Decommissioning Focus Area, Federal Energy Technology Center. The Principal Investigator, the Florida International University (FIU) Collaborator, and students at FIU would like to thank Dr. Paul Hart and Steve Bossart for providing us with the opportunity and support to work on this project. 



\section{TABLE OF CONTENTS}

ACRONYMS iv

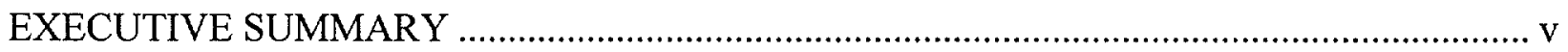

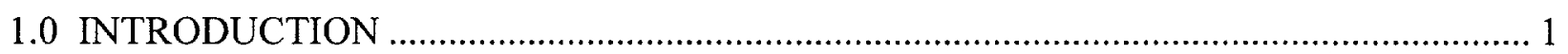

1.1 PurPose OF THIS INVESTIGATION............................................................... 1

Literature Search to Determine Pipe Remediation Problem Set............................... 1

Determine Applicable Regulatory Policies and Procedures ...................................... 2

Review of Decontamination and Characterization Technologies.............................. 2

Perform Bench-Scale Testing to Obtain Comprehensive and Comparable Data ......... 2

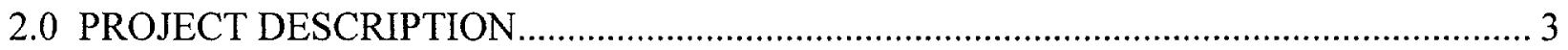

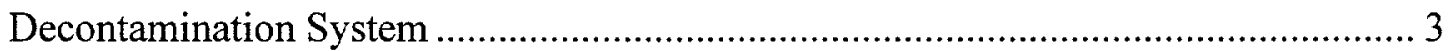

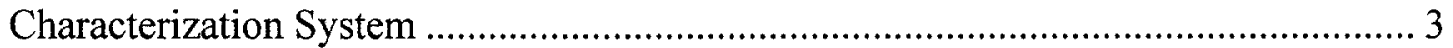

Integration and Field Implementation.......................................................... 3

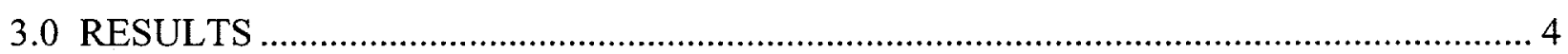

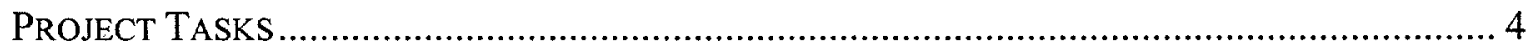

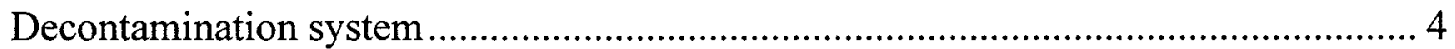

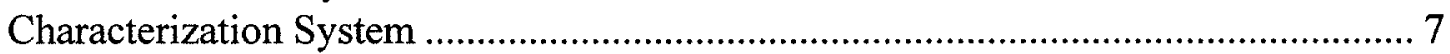

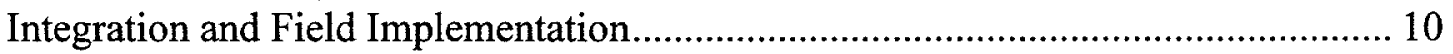

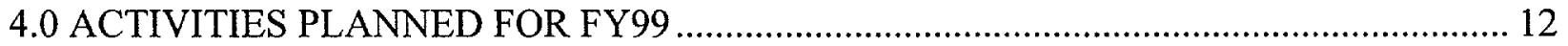

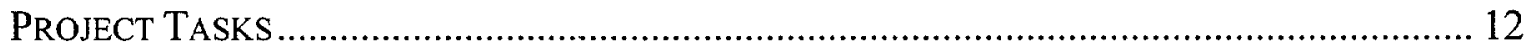

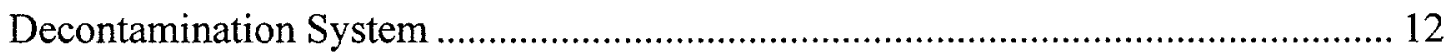

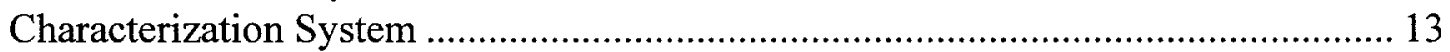

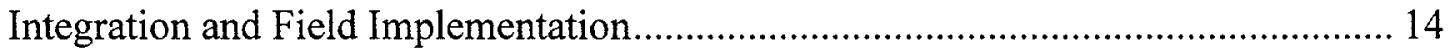

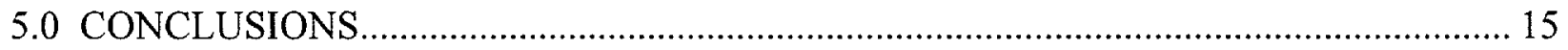

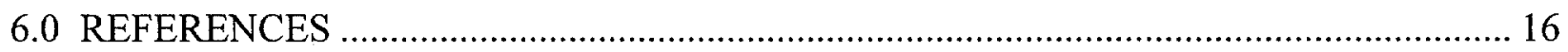

\section{APPENDIX}




\section{ACRONYMS}

D\&D Deactivation and Decommissioning

DOE U.S. Department of Energy

DOE-EM U.S. Department of Energy-Environmental Management

DOE-OST U.S. Department of Energy-Office of Science and Technology

FIU Florida International University

FIU-HCET Florida International University's-Hemispheric Center for Environmental Technology

FY97 Fiscal Year 1997

FY98 Fiscal Year 1998

HCET Hemispheric Center for Environmental Technology

RAPIC Remedial Action Program Information Center 
The decontamination and decommissioning (D\&D) of 1200 buildings within the U.S. Department of Energy-Office of Environmental Management (DOE-EM) complex will require the disposition of miles of pipe. The disposition of large-bore pipe, in particular, presents difficulties in the area of decontamination and characterization. The pipe is potentially contaminated internally as well as externally. This situation requires a system capable of decontaminating and characterizing both the inside and outside of the pipe. Current decontamination and characterization systems are not designed for application to this geometry, making the direct disposal of piping systems necessary in many cases. The pipe often creates voids in the disposal cell, which requires the pipe to be cut in half or filled with a grout material. These methods are labor-intensive and costly to perform on large volumes of pipe. Direct disposal does not take advantage of recycling, which could provide monetary dividends. To facilitate the decontamination and characterization of large-bore piping and thereby reduce the volume of piping required for disposal, a detailed analysis will be conducted to document the pipe remediation problem set (completed FY97); determine potential technologies to solve this remediation problem set (completed FY97); design and laboratory test potential decontamination and characterization technologies (completed FY97); fabricate a prototype system (FY98 and FY99); provide a cost-benefit analysis of the proposed system ( preliminary completed FY98); and deploy the system (FY99 and beyond).

The Large-Bore Decontamination Process consists of three main systems: the decontamination system, the characterization system, and the material handling system integration system. The decontamination system is further segregated into two modules: the decontamination module and the ventilation module. The development of project tasks and documents follows this general outline to ensure consistency in understanding the project flow.

This report summarizes the activities performed during FY98 and describes the planned activities for FY99. Accomplishments for FY98 include completing the final design of the decontamination module, design and procurement of the ventilation module, the screening of potential characterization technologies, procurement of the characterization system, and the completion of a preliminary cost-benefit analysis. 


\subsection{INTRODUCTION}

The D\&D of 1200 buildings in the DOE-EM complex will require the disposition of miles of pipe. This pipe ranges in size, material type, type of contaminant, and coating. The disposition of large-bore pipe presents difficulties in the areas of decontamination, characterization, and disposition. The pipe is potentially contaminated internally as well as externally. This situation requires a system capable of decontaminating and characterizing the interior and exterior of the pipe. Current decontamination and characterization systems are not designed to meet the remediation goals for large-bore pipe, necessitating, in many cases, direct disposal of piping systems. The pipe creates voids in the disposal container and in the disposal cell, requiring the pipe to be cut in half or filled with a grout material. These methods are labor-intensive and costly to perform on large volumes of pipe. Also, direct disposal does not take advantage of recycling, which would provide monetary dividends during the disposition of large-bore pipe.

\subsection{PURPOSE OF THIS INVESTIGATION}

The decontamination and characterization of large-bore pipe is difficult because of the various geometries and diameters of pipe and its different material types. A robust decontamination system must be capable of adapting to different pipe diameters (project scope is 6 inches to 24 inches), cleaning surfaces with various surface conditions and material types (i.e., painted, rusted, carbon steel, or stainless steel) and be cost-effective to operate and maintain. The characterization system must be capable of handling the different pipe parameters and detecting contamination on the inside and outside surfaces. It must also operate in a cost-effective manner. Current technology options do not provide a robust system to meet these objectives.

The purpose of this project is to verify the need for this technology through determining quantities of pipe available for decontamination (completed FY97), perform a technology screening process to select technologies for decontamination (completed FY97) and characterization (completed FY98), perform treatability studies to collect required performance data (completed FY97), and design and fabricate a prototype system to decontaminate and characterize the internal and external surfaces of large-bore pipe. A field-mobile system capable of performing decontamination and characterization operations will be the main deliverable for this project.

A summary of activities completed during FY97 is provided to understand the project development and implementation process. For further information related to the activities completed during FY97, please refer to the Fiscal Year 1997 Year-End Report for the August 1996 to October 1997 Period for LARGE-BORE PIPE DECONTAMINATION.

\section{Literature Search to Determine Pipe Remediation Problem Set}

Rough order-of-magnitude quantities were obtained from Hanford and Fernald, including $150,000 \mathrm{~m} 3$ of pipe at Hanford and $5,880 \mathrm{~m} 3$ of pipe at Fernald. Obtaining quantities from other DOE operations offices would require a significant level of effort; therefore, Florida International University's Hemispheric Center for Environmental Technology (FIU-HCET) and the 
Deactivation and Decommissioning Focus Area (DDFA) decided that acquiring the additional information would not be cost-effective and concluded that significant volumes of pipe exist to warrant the continuation of the project.

\section{Determine Applicable Regulatory Policies and Procedures}

The list of regulations that govern the fabrication and operation of the pipe decontamination and characterization system was compiled. This list was given to the potential technology vendors to aid in proposal development, design, equipment fabrication, and system evaluation.

\section{Review of Decontamination and Characterization Technologies}

The review and collection of data for possible decontamination and characterization options for large-bore pipe are complete. Based on the information reviewed, an initial screening method used for pipe decontamination technologies was developed and implemented. The initial criteria include the technology's ability to meet the required clean, near-white metal surface finish 1 on the interior or exterior of a pipe and the system's potential to be developed into a field-mobile system. Seventeen decontamination technologies were evaluated as part of the initial screening process. Of the technologies screened, six technologies were selected for further evaluation; these six were then narrowed to one technology: grit blasting.

The literature survey of technologies capable of characterizing the interior and exterior of largebore pipe is complete, and the resulting list detailing 21 technologies was prepared.

\section{Perform Bench-Scale Testing to Obtain Comprehensive and Comparable Data}

Carbon steel samples were sent to two laser ablation vendors to obtain an indication of whether laser ablation can achieve a near-white metal finish on a painted carbon steel surface. Both vendors' results were similar, indicating the surface could not be cleaned to a near-white metal surface with the laser systems deployed. Based on this review, laser ablation was eliminated from further consideration.

The manufacturer-recommended honing devices for 4-in., 6-in., and 10-in. diameter pipes were obtained from Brush Research Manufacturing Company and evaluated on non-contaminated carbon steel at the FIU-HCET test facility. The device was operated inside the test pipe as directed by the manufacturer. The technology was able to achieve a near-white metal finish; however, the honing device showed excessive wear and would not be practical for high volume, high production rate applications.

Based on these bench-scale tests, laser ablation and the honing device were eliminated from further consideration.

\footnotetext{
1 "A cleaned, near-white surface, when viewed without magnifications, shall be free of all visible oil, grease, dirt, dust, mill scale, rust, paint and oxides, corrosion products, and other foreign matter, except for staining. Staining shall be limited to no more than 5 percent of each square inch of the surface area and may consist of light shadows, slight streaks, or minor discolorations caused by rust stains, mill scale stains, or previously applied paint stains." (Structural Steel Painting Council, 1991, Surface Preparation Specifications, Structural Steel Painting Council, Pittsburgh, PA, pp. 53-56.)
} 


\subsection{PROJECT DESCRIPTION}

The following tasks were scheduled for completion during FY98. The preliminary engineering was performed in FY97, with the majority of the procurement, fabrication, and system testing activities occurring during FY98 and FY99. The tasks are segregated into three major categories: decontamination system, characterization system, and integration and field implementation of the two systems.

\section{Decontamination System}

Task 1. Title I Design

Task 2. Title II Design

Task 3. Title III Design

Task 4. Operations

Task 5. Close-Out

\section{Characterization System}

Task 1. Screen Potential Characterization Technologies

Task 2. Design and Evaluate EIC Technology

Task 3. Procurement of Characterization System

Task 4. Title I Design

Task 5. Title II Design

Task 6. Title III Deign

Task 7. Operations

Task 8. Close-Out

\section{Integration and Field Implementation}

Task 1. Integrate Decontamination and Characterization

Task 2. Field Implementation at a Selected DOE Site. 


\subsection{RESULTS}

The 15 tasks presented in Section 2 "Project Description" and in the FY98 Project Technical Plan (PTP) are presented below. The italicized text indicates the task description presented in the FY98 PTP. The results of each task and any deviations are presented in the paragraphs that follow. The project tasks have been grouped into three categories: Decontamination System, Characterization System, and the integration and field implementation of the two systems.

\section{PROJECT TASKS}

\section{Decontamination system}

\section{Task 1. Title I Design}

An initial design of the system and a review of estimated costs for completion will be performed. FIU-HCET will also approve the expenditure of long lead-time procurement items.

The initial design for the decontamination system was completed on November 20, 1997. The initial design consists of an initial layout of the decontamination system confirming the system will conform to the requirement of fitting within transportable strong tight containers. Overall dimensions for the blast cabinet, conveyors, and material conveyance systems were specified. The initial design also indicated material flow paths and the preliminary ventilation requirements. The overall safety requirements and interlocks were also defined. The overall configuration of the decontamination system is shown in Figure 1.

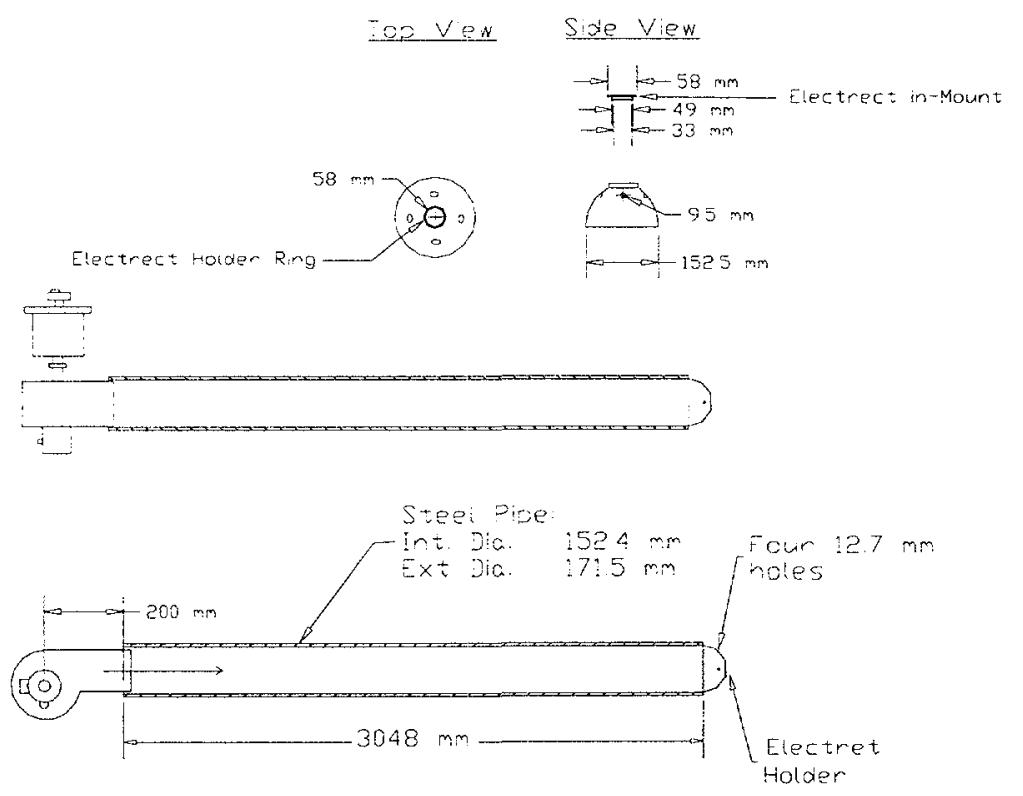

Figure 1. Overall configuration of decon module. 
The decontamination system parameters are as follows:

- A four-wheel centrifugal system will be used to decontaminate exterior surfaces.

- An air-operated dual-pressure vessel system with a nozzle and lance will be used to decontaminate the interior surfaces of the pipe.

- Exterior surfaces of the pipe will be decontaminated followed by internal surfaces.

- The decontamination module will be housed in a 40 feet long by 8 feet wide by 10 feet tall strong tight container. A removable module that is fastened to the top of the strong tight container is required to house the bucket elevator. This module is removed during transportation.

- Steel grit will be used for the decontamination media.

- The ventilation module will be housed in a separate strong tight container. The ventilation module consists of standard grit blasting dust collector and a HEPA-filtered module for final filtration prior to exhausting the air.

- The strong tight container for the ventilation module will be 38 feet long by 8 feet wide by 10 feet tall.

\section{Task 2. Title II Design}

FIU-HCET will review and approve the final design of the decontamination system and review estimated costs for completion.

The final design for the decontamination system was completed on June 15, 1998. The detailed design consisted of a narrative and a set of design prints. The final design submittals indicate the requirements set forth in the performance specifications will be met or exceeded. These performance specifications require the following:

- System must handle 6 inch in diameter through 24-inch diameter pipe.

- System must handle four-foot to ten-foot length pipe.

- System must be capable of achieving a near white metal finish on structural steel.

- System must handle a minimum dimension of 2 inches through 24 inches structural steel shapes.

- System must handle ten-foot length structural steel.

- The output of the system must produce a surface that is free of moisture and dust.

- Process rate must be 3 to 5 feet per minute for 6-inch diameter pipe.

- The ventilation system must follow ANSI 509 and 510 standards for nuclear systems.

- The system must have nuclear grade bag-in bag-out HEPA filtration as the final stage of filtration.

- All spent media and waste from the pipe must be collected in standard waste drums.

- All waste must be dry and be considered non-hazardous. 
- System components must fit inside a nuclear grade container or containers.

- The system must be field-mobile.

Figure 1 illustrates the overall configuration of the decontamination module and Figure 2 is a representation of the ventilation module configuration. The design drawings were reviewed by FIU-HCET and comments were incorporated prior to starting Title III design.

Title II also included the development of the layout of the strong tight containers for the decontamination module and the ventilation module. The layout of each of these containers was completed during FY98. The procurement of the ventilation module strong tight container was completed during FY98 with the detailed design and fabrication to occur during the first quarter of FY99. The completion of the detailed design and fabrication for the decontamination system strong tight container will be completed during the first quarter of FY99.

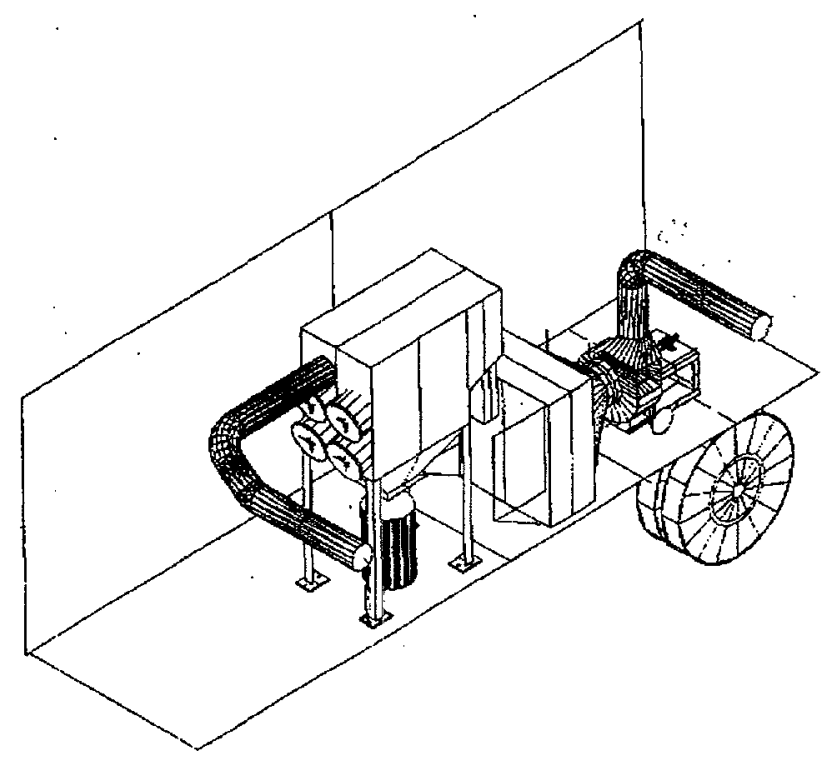

Figure 2. Ventilation module arrangement.

\section{Task 3. Title III Design}

FIU-HCET will monitor the fabrication of the system to ensure that the specifications and design drawings are being followed.

During FY98 the majority of the fabrication work was completed for the decontamination and the ventilation modules. The remainder of the Title III design work will be completed during the first quarter of FY99. A total of four trips were made to the manufacturing facilities to ensure the design drawing and performance specifications were met. All fabrication activities meet or exceed the design drawings and performance specifications. 


\section{Task 4. Operations}

FIU-HCET will witness the cleaning of five tons of pipe ranging in diameter from 6 to 24 inches. The vendor will develop a detailed operations and maintenance manual. Remediation service companies will be invited when the system is tested to solicit input and determine potential technology transfer partners.

The delay in the completion of the Title III design for the decontamination system postponed the execution of this task until FY99.

\section{Task 5. Close-Out}

Upon successful field-testing, the system will be transported to FIU-HCET, and five people will be trained to operate and maintain the system.

The delay in the completion of the Title III design for the decontamination system postponed the execution of this task until FY99.

\section{Characterization System}

\section{Task 1. Screen Potential Characterization Technologies}

A detailed review will be performed on the preliminary list of characterization technologies to determine the viable technology options. This assessment may involve laboratory testing of technologies in which detailed performance data is required to ensure the viability of the system. The technologies that pass the screening process will be part of the bidders list for the request for proposal.

Based on the review performed by FIU-HCET and an independent consultant a total of five companies passed the screening of the 21 technologies identified during the review of possible characterization technologies. The screening criteria included the following:

- System must be capable of characterizing pipe and structural steel meeting DOE Order 5400.5 Reg. Guide 1.86 for alpha, beta, and gamma emitters

- System must characterize 6 inch in diameter through 24 -inch diameter pipe made of different materials excluding aluminum.

- System must characterize two foot to ten-foot length sections of pipe.

- System must characterize structural steel shapes with width dimensions from 2 inches to 24 inches.

- System must characterize two-foot to ten-foot length sections of structural steel.

- The operation of the system must not result in contamination of personnel, equipment, or create airborne radioactive contamination.

- The system must be field-mobile.

- The system must be able to be calibrated in the field. 
The five technologies, which potentially meet the initial criteria, were provided performance specifications and a request for proposal as identified in Task 3 of the Characterization System Section.

\section{Task 2. Design and Evaluate EIC Technology}

The EIC technology will be further developed for application to characterizing the internals of pipe. This includes reviewing the system from a fluid mechanics viewpoint, evaluating the system at different flow rates, and evaluating different radioactive sources and dimensions of pipe. Equipment parameters will be reviewed to ensure the system has the appropriate limits of detection and production rates along with other performance factors such as case of operation, and flow control.

The design and evaluation of the EIC is prepared and presented in a separate final report.

\section{Task 3. Procurement of Characterization System}

Detailed performance specifications and a request for proposal will be developed and sent to the potential vendors. The specifications will detail minimal detection limits, contaminants of concern, production rates, and deployment requirements. The bid responses that meet the performance specifications with the lowest costs will be selected to design, fabricate, and test the characterization system overseen by FIU-HCET.

Detailed performance specifications were developed and included in an invitation to bid that was sent to the five technology vendors identified in the initial screening and to seven additional vendors requesting the invitation to bid. Of the twelve invitations to bid sent out one response was received. The bid was reviewed and found to be technically complete. Funding issues required the delay in the award of the contract for a total of four months. The kick-off meeting for the characterization system development was held during August 997. The delay in the award of the contract requires the adjustment in the schedule for the completion of the design, fabrication, integration, and field implementation activities.

\section{Task 4. Title I Design}

Title I design will require producing initial design drawings and obtaining the approval of longterm procurement items.

Title I design submittal was made during the final week of FY98. The review of the Title I submittal will occur during the first quarter of FY99. Figure 3 is a conceptual view of the overall arrangement of the characterization system. 


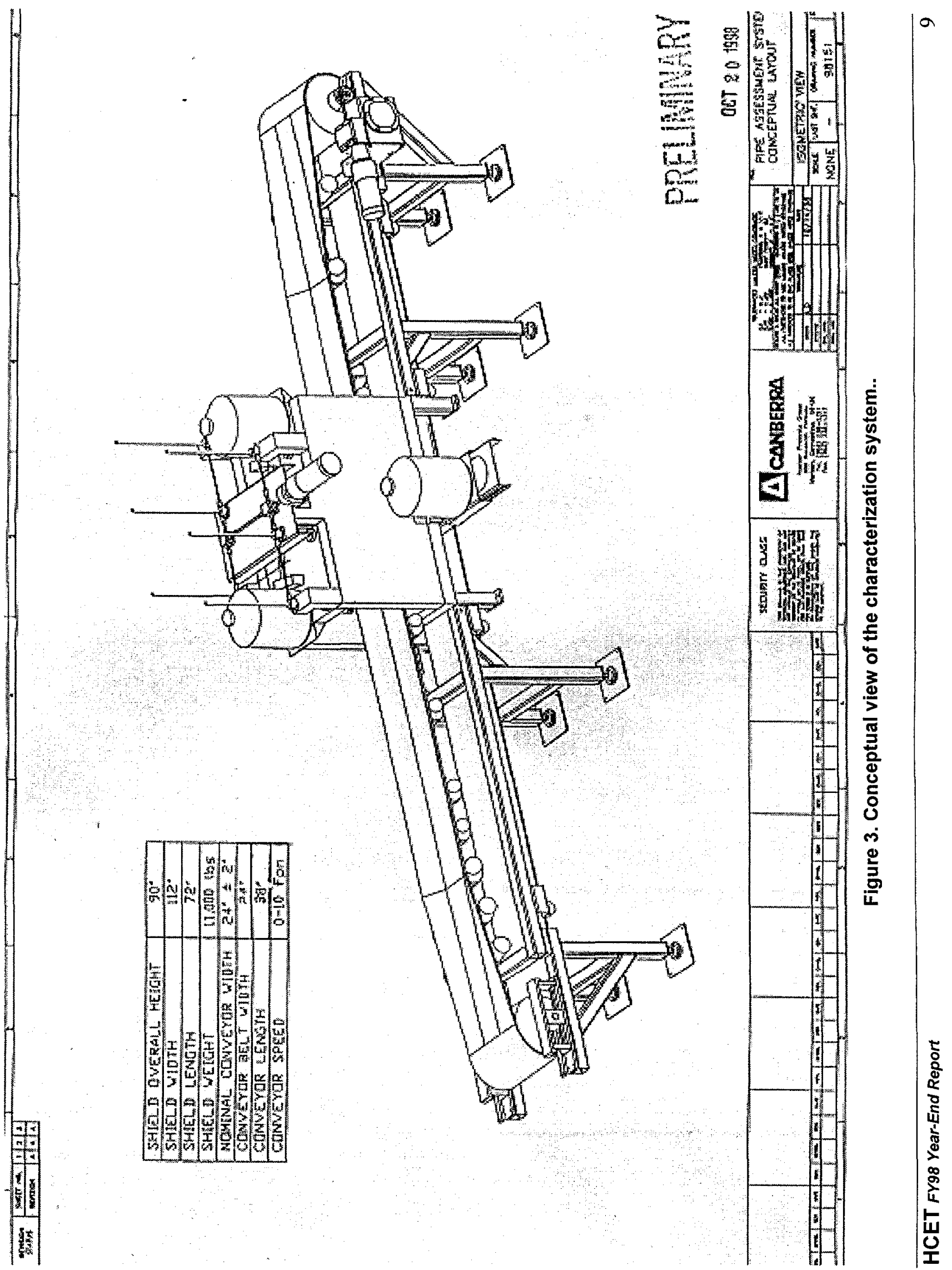




\section{Task 5. Title II Design}

FIU-HCET will review and approve the final design of the characterization system and review estimated costs to complete it.

The delay in the award of the contract for the characterization system has postponed the execution of this task until FY99.

\section{Task 6. Title III Design}

FIU-HCET will monitor the fabrication of the system to ensure the specifications and design drawings are being followed.

The delay in the award of the contract for the characterization system has postponed the execution of this task until FY99.

\section{Task 7. Operations}

FIU-HCET will witness the characterization of five tons of pipe ranging in diameter from 6 to 24 inches. A detailed operations and maintenance manual will be written by the vendor describing the calibration and operation process of the characterization system. Remediation service companies will be invited when the system is tested to solicit input and determine potential technology transfer partners.

The delay in the award of the contract for the characterization system has postponed the execution of this task until FY99.

\section{Task 8. Close-Out}

Upon successful field-testing, the system will be transported to FIU-HCET, and five people will be trained on the operation and maintenance of the characterization system.

The delay in the award of the contract for the characterization system has postponed the execution of this task until FY99.

\section{Integration and Field Implementation}

\section{Task 1. Integrate Decontamination and Characterization Systems}

The decontamination and characterization systems will be integrated during all steps of their design and fabrication. Prior to field implementation at a DOE site, the systems will be tested to ensure all material handling, power, and system layout issues are resolved to ensure that the system operates as an integrated system. The system will be operated at the FIU-HCET test facility to complete this task.

The delay in the award of the contract for the characterization system has postponed the execution of this task until FY99. Figure 4 illustrates the overall system layout and process flow. 


\section{Task 2. Field Implementation at a Selected DOE Site.}

With the help of the D\&D Focus Area manager, a DOE remediation project will be initiated on a minimum of ten tons of pipe to operate the system at a selected site. Remediation service companies will be invited when the system is tested to solicit input and finalize potential technology transfer partners.

The delay in the award of the contract for the characterization system has postponed the execution of this task until FY99.

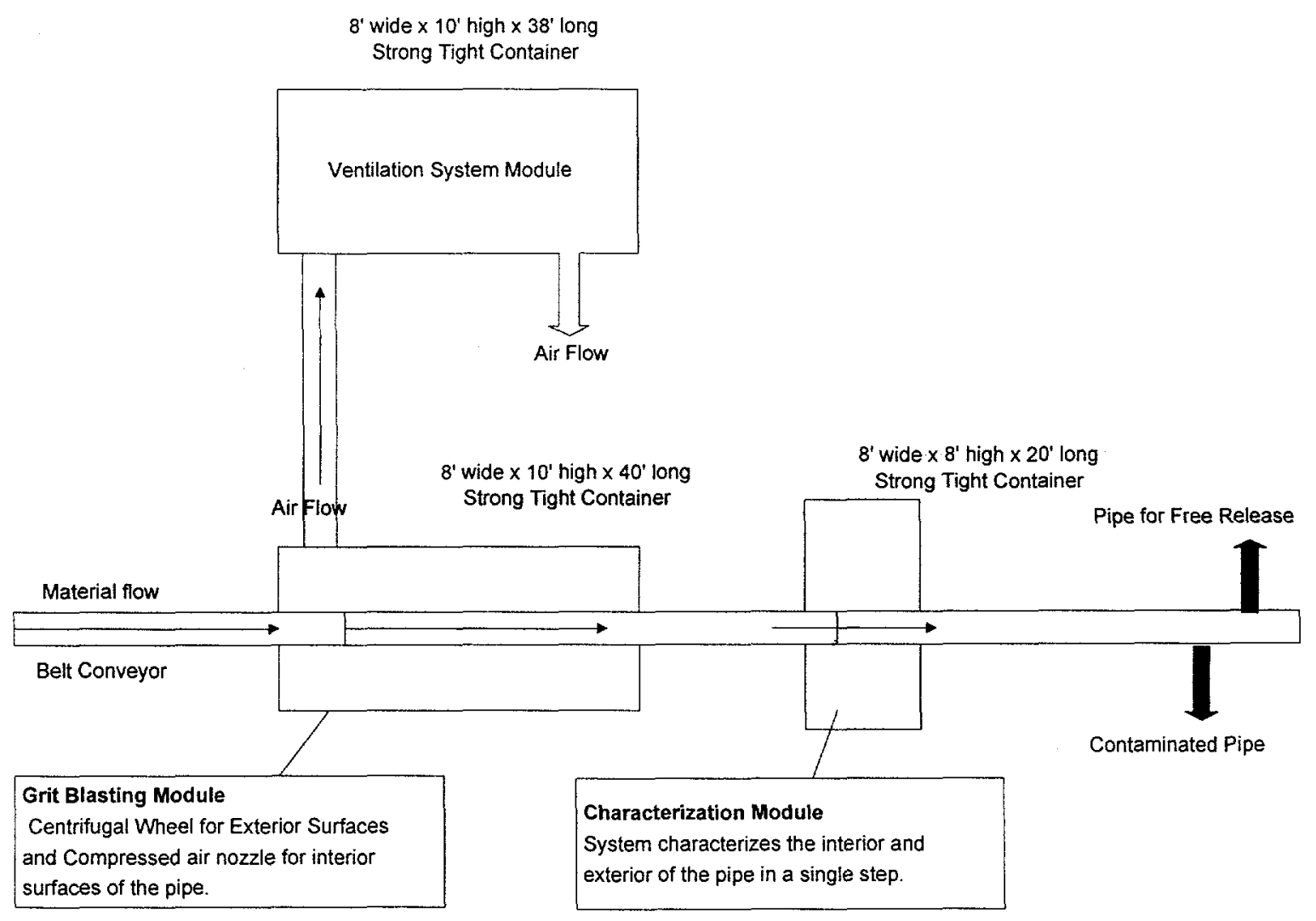

Figure 4. Product flow diagram.. 


\subsection{ACTIVITIES PLANNED FOR FY99}

The following tasks are scheduled for completion during FY99. The project tasks have been grouped into three categories: decontamination system, characterization system, and integration of the two systems.

\section{PROJECT TASKS}

\section{Decontamination System}

\section{Task 1. Title III Design}

FIU-HCET will monitor the fabrication of the decontamination and ventilation modules and the installation of the equipment into the transportation containers. Periodic design reviews will be held to ensure the fabrication is on schedule and meets the performance specifications. Operation and maintenance procedures will be developed for each major component.

\section{Task 2. Procurement of the Transportation Containers}

Strong tight transportation containers will be procured, designed, and fabricated for the decontamination module and designed and fabricated for the ventilation module. The decontamination and ventilation equipment will be permanently housed in these containers. The containers will meet the requirements of 49 CFR for the transport of low-level radioactive waste. The containers will be equipped with penetrations and access ports and doors to facilitate operations and routine maintenance.

\section{Task 3. Procurement of transportation trailers}

A total of five transportation trailers will be required to move the Ex-Situ Large-Bore Pipe Characterization and Decontamination System to different project locations. Two double-drop trailers are required, one each for the decontamination system and the ventilation system. Three standard height trailers are required one for the characterization system and two for the material handling system. These five transportation trailers will be procured, and the individual systems will be installed on each trailer.

\section{Task 4. Field Evaluation}

FIU-HCET will witness the cleaning of five tons of pipe ranging in diameter from 6 to 24 inches. Remediation service companies and Department of Energy representatives will be invited to solicit input and to gain an understanding of the capabilities of the system.

\section{Task 5. Close-out}

Upon successful field-testing, the system will be transported to FIU-HCET, and five people will be trained on the procedure to operate and maintain the system. 


\section{Task 1.6 Exploration of Deployment Opportunities for Decontamination System}

The field-ready decontamination system is scheduled for completion four months prior to the completion of the characterization module. This time period provides an opportunity to implement the decontamination system independently of the characterization system. Opportunities will be reviewed and contracts will be placed for the implementation of the decontamination system.

\section{Characterization System}

\section{Task 1. Title I Design}

Title I design will require producing initial design specifications and drawings, a software specification document, and obtaining the approval of long-term procurement items. FIU-HCET will review and approve the Title I design prior to implementing Title II design.

\section{Task 2. Title II Design}

FIU-HCET will review and approve the final design of the characterization system and review estimated costs to complete the characterization system. FIU-HCET will review and approve the Title II design prior to implementing Title III design.

\section{Task 3. Title III Design}

FIU-HCET will monitor the fabrication of the system to ensure the specifications and design drawings are being followed. Fabrication also includes hardware integration and software coding. Periodic design reviews will be held to ensure the fabrication is on schedule and meets the performance specifications. An operation and maintenance procedure will be developed for the characterization system.

\section{Task 4. Field Evaluation}

FIU-HCET will witness the characterization of five tons of pipe ranging in diameter from 6 to 24 inches and different types of contaminants. Remediation service companies and Department of Energy representatives will be invited when the system is tested to solicit input and to gain an understanding of the capabilities of the system.

\section{Task 5. Close-Out}

Upon successful field-testing, the system will be transported to FIU-HCET, and five people will be trained on the operation and maintenance of the characterization system. 


\section{Integration and Field Implementation}

\section{Task 1. Integrate Decontamination and Characterization Systems}

The decontamination and characterization systems will be integrated during all steps of their design and fabrication. Prior to field implementation at a DOE site, the systems will be tested to ensure all material handling, power, and system layout issues are resolved to ensure that the system operates as an integrated system. The system will be operated at the FIU-HCET test facility to complete this task.

\section{Task 2. Field Implementation at a Selected DOE Site}

With the help of the D\&D Focus Area manager, a DOE remediation project will be initiated on a minimum of ten tons of pipe to operate the system at a selected site. Remediation service companies and Department of Energy representatives will be invited when the system is tested to solicit input and to gain an understanding of the capabilities of the system. 


\subsection{CONCLUSIONS}

Through the selection and initial design of the ex-situ large-bore pipe decontamination and characterization system, the project shows the promise of producing a cost-effective alternative to the direct disposal of piping systems. A cost-benefit analysis has been completed for the decontamination and characterization systems. Broad assumptions were made related to the characterization system because the design and operations costs are not known at this time. The cost-benefit analysis shows a significant savings in the operation of this system over the option of direct disposal. The schedule set forth for the design, procurement, and fabrication of the characterization and decontamination system has been delayed from the baseline schedule established in FY97. These delays were primarily due to an increased amount of design time required to ensure the project meets the overall project objective and the lack of fundamental technologies to select from during the technology selection and procurement process. 


\subsection{REFERENCES}

U.S. Department of Energy, 1990, Radiation Protection of the Public and the Environment, DOE Order 5400.5, Office of Environment, Safety and Health, Washington, D.C.

U.S. Department of Energy, 1996, Decontamination and Decommissioning Focus Area Results of the National Needs Assessment, U.S. Department of Energy-Office of Environmental Management, Washington, D.C.

U.S. Department of Energy, 1996, Decontamination and Decommissioning Focus Area Technology Summary, DOE/RL-93-0, U.S. Department of Energy-Office of Environmental Management, Washington, D.C.

U.S. Nuclear Regulatory Commission, 1982, Regulatory Guide, Termination of Operating Licenses for Nuclear Reactors, Regulatory Guide 1.86, Washington, D.C. 


\section{APPENDIX}

\section{MEASUREMENT OF ALPHA CONTAMINATION INSIDE LARGE-BORE PIPES USING ELECTRET ION CHAMBERS}




\title{
MEASUREMENT OF ALPHA CONTAMINATION INSIDE LARGE-BORE PIPES USING ELECTRET ION CHAMBERS
}

\author{
S.K. Dua, J. Boudreaux, L. Garcia, S.K. Biswas, R. Rose and M.A. Ebadian \\ Hemispheric Center for Environmental Technology \\ Florida International University \\ 10555 W. Flagler St., EAS 2100 \\ Miami Florida 33174 USA
}

The decontamination and decommissioning of a large number of buildings within the U.S. Department of Energy-Office of Environmental Management complex will require the disposition of miles of pipe. The disposition of large-bore pipe, in particular, presents difficulties in the area of decontamination and characterization. The pipe is potentially contaminated internally as well as externally. This situation requires a system capable of decontaminating and characterizing both the inside and outside of the pipe. Current decontamination and characterization systems are not designed for application to this geometry, making the direct disposal of piping systems necessary in many cases. Direct disposition methods are laborintensive and costly to perform on large volumes of pipe. Direct disposal does not take advantage of recycling, which could provide monetary dividends. DOE will save millions of dollars if it could be demonstrated that $20 \%$ of the pipe has contamination less than free release level. Therefore, the D \& D community has an urgent requirement for low-cost methods for measuring alpha contamination in pipes.

Direct measurement of alpha contamination inside pipes of different bores using alpha probes is difficult due to small range $(\sim 5 \mathrm{mg} \mathrm{cm}$ or $\sim 4 \mathrm{~cm}$ in air $)$ of alpha particles. Therefore, an indirect method is used for measurement of alpha contamination. In this method ions produced by alpha radiation are transported by flowing air into an electret ionization chamber located at the end of the pipe and measured. The rate of reduction of the electret surface charge due to collection of ions is a measure of the alpha contamination inside the pipe. Calibration is accomplished by locating an alpha source of known strength along the length of a pipe and determining the response factors (change of electret voltage per disintegration). Using this technique, it is possible to measure in 10 minutes a uniform alpha contamination in $152-\mathrm{mm}$ and $304-\mathrm{mm}$ diameter pipes at the DOE release limit of $1 \mathrm{dpm} \mathrm{cm}^{-2}$ for transuranics.

\section{INTRODUCTION}

Measurement of alpha contamination is difficult because of the short range of alpha particles $(\sim 5$ $\mathrm{mg} \mathrm{cm}{ }^{-2}$ or $\sim 4 \mathrm{~cm}$ in air). Therefore, the detectors used to measure alpha radiation have either no window or an extremely thin window $\left(<1 \mathrm{mg} \mathrm{cm}^{-2}\right.$ of mylar). Such detectors are suitable only for measurement of contamination on the external smooth surfaces of objects. In decontamination and decommissioning, there is a requirement to measure the alpha contamination on the internal surface of pipes in which plutonium, uranium, radium, and other radioactive materials were handled. Conventional method used for measurement of alpha contamination is to move a detector in the pipe and scan the surface. This method has limited success because it is difficult 
to place a detector in close contact with internal surfaces of pipes of various bores and lengths.

Recently, Science \& Engineering Associates, Inc. (Kendrick and Cremer 1996) have demonstrated that a silver activated zinc sulfide detector deployed in the pipe explorer can be used for measurement of alpha contamination in pipes. Another method, developed by Los Alamos National Laboratory (Rawool-Sullivan and Vaccarella 1994; Rawool-Sullivan et al. 1996; Kasper 1998), is based on ion transport technology. In this technique ions produced by alpha radiation are transported by flowing air to the electrode inside the detector for ion collection. The collection electrode is connected to a sensitive electrometer. The current recorded by the electrometer provides a measure of the contamination level on the interior surfaces. Using ion transport technology Kotrappa and Stieff (1997) and Dua et al. (1997) have used an electret ion chamber for measurement of contamination inside $150-\mathrm{mm}$ diameter pipes. They have shown that an alpha contamination of $2.2 \mathrm{dpm} \mathrm{cm}^{-2}$ can be measured in 15 minutes. The aim of the present study is to improve the measurement sensitivity of the system and extend the measurements to $30-\mathrm{mm}$ bore pipes.

\section{ELECTRET ION CHAMBER TECHNOLOGY}

An electret ion chamber (EIC) consists of an electret loaded into an electrically conducting plastic chamber of a known air volume, collectively called the EIC, and a charge reader. The electret serves both as a source of voltage for the collection of ions produced by radiation in the air volume and as a quantitative sensor of this ionization. As a result of the collection of ions on the electret's surface, its surface charge diminishes. This reduction in charge over a known time interval provides a quantitative measure of the radiation. Measurement of the surface charge is performed using the shutter method, also called capacitative probe method. The EIC is a rugged device and is not affected by varying humidity and temperature.

For most of the applications the radiation to be measured enters the chamber through a window (Kotrappa et al. 1992; Meyer at al. 1994; Meyer at al. 1995; Dua et al. 1998) and produces ions in the chamber volume. In the ion transfer technology ions produced by radiation are transferred into the sensitive volume of a windowless electret chamber by flowing air, thus enabling collection of ions prior to their recombination. The collection of ions on electret results in a drop in its charge. This drop in charge in known time is a measure of radiation.

\section{MATERIALS AND METHODS}

\section{Experimental Setup}

For characterization of pipe internals, two systems were fabricated. The first system was similar to the one used earlier (Dua et al. 1997) except for the diameter of the four holes, length of pipe, and air flow control. The holes in the new system were of $12.7-\mathrm{mm}$ diameter as against $9.5 \mathrm{~mm}$ in the previous system. The length of the test pipe was bigger $(3.05 \mathrm{~m}$ as against $1.86 \mathrm{~m})$. The air flow control was also better. In this system, called a four-hole system, filtered air was pushed in from one end of the pipe and exhausted through four openings in the $960-\mathrm{mL}$ EIC at the other end (Figure 1). In the second system, called a coaxial system, another pipe of smaller diameter 
was placed coaxial inside the test pipe (Figure 2). The inner pipe was commercially available pipe of standard bore size. The dimensions of the inner pipe were selected so that the annular space between the pipes (test-pipe and inner-pipe) was approximately $4.5 \mathrm{~cm}$, the maximum range in air of most encountered alpha particles. Filtered air entered close to one end of the pipe through the annular space between the pipes, traveled in the annular space, turned at the end of the annular space, entered the inner pipe through its end near the detector, and exited through its end, close to the air inlet. The air leaving this system was filtered to prevent release of any contaminants into the environment from the pipes that might become airborne. An EIC without openings was mounted close to the end of the pipe where the air turned. Ions produced by an alpha source mounted inside the test pipe and transferred by flowing air were brought close to the EIC and were collected by the electret.

\section{Experimental Protocol}

An electroplated ${ }^{-241} \mathrm{Am}$ source of known radioactivity was fixed at a marked position on a thin $10-\mathrm{mm}$ wide strip of a measuring tape using double-sided adhesive tape. This measuring tape was positioned flush inside the pipe such that the source was at a known distance from the chamber and alphas from the source were emitted into the air volume. A used electret was loaded in the electret and the blower was turned on. After 60 minutes of flow, the velocity of the air leaving $12.7-\mathrm{mm}$ diameter holes in the chamber (four-hole system) or leaving inner pipe (coaxial system) was measured. An electret was selected, and its initial voltage was measured. The used electret was removed from the electret holder and the selected electret with measured initial voltage was loaded. It was exposed for a known time, removed from the holder, and its voltage (final voltage) was measured again. Depending on the number of ions collected the final voltage for an exposure will be lower than the initial voltage. For the next exposure this final voltage becomes the initial voltage. Such measurements (initial and final voltages for an exposure time) were repeated for decreasing electret voltage till the electret voltage decreased below $200 \mathrm{~V}$, and a correlation was obtained between change in volt per disintegration (called response factor) and mid-point voltage, MPV (the average of the initial and the final voltage of an exposure).

\section{Calibration}

Calibration of the EIC was accomplished by locating an alpha source along the length of a pipe and determining the response factors (change of volts per disintegration). Calibrations were performed for different voltage on electret, different locations of the source, different flow rates, and different source strengths.

\section{RESULTS AND DISCUSSION}

\section{Four-hole system}

As described earlier, calibration of the electret ion chambers was performed by placing inside the test pipe an alpha source of known strength at a fixed distance from the detector. At a given flow rate, initial voltage on the electret was measured. It was exposed for a known time, and then the final voltage was measured. Thus, a change in voltage per unit time at a given mid-point voltage, MPV (mean of the initial and the final electret voltage), was obtained. Change in voltage per 
minute divided by source radioactivity in disintegration per minute gives change in voltage per disintegration (or response) at a given mid-point voltage. Exposure of the electret was continued. Each time response was determined corresponded to its MPV. Figure 3 gives response curves (response vs. MPV plots) of short-term electrets (thickness: $1.274 \mathrm{~mm}$ ) for the earlier system (Dua et al. 1997) with 4 holes of $9.5-\mathrm{mm}$ diameter and the current system with four 12.7-mm holes. These measurements were performed under identical conditions of flow velocity, source detector distance, and source strength. It can be seen from this figure that the response of the $12.7-\mathrm{mm}$ hole system is higher by nearly $50 \%$ than that of the $9.5-\mathrm{mm}$ diameter holes system. All further experiments with the four-hole system were done using the chamber with 12.7-mm diameter holes.

Figure 4 shows the response of the four-hole system obtained by placing an alpha source at a fixed distance, but at different air flow velocities through the holes. Figure 4 gives a response curve (a plot of response and MPV) at different flow rates. It was observed that the response decreases as the flow rate increases.

Table 1 shows the response for various distances of the source from the test pipe-end near the detector. All experiments were done at an average flow velocity of a $670 \mathrm{~cm} \mathrm{~s}-1$ through the holes. It can be seen that the response of the EIC decreases as the source is moved away from the detector. Ions generated at large distances spend more time during their travel toward the electret, resulting in increased loss of ions due to recombination (Knoll 1989).

Influence of alpha source strengths on the response was studied by placing alpha sources of different known radioactivity at a fixed distance of $0.76 \mathrm{~m}$ from the pipe-end close to the electret. It was observed that response (change in volt per disintegration) decreased (Figure 5) as the source strength increased. The decrease in response was due to increased loss of ions at high ion densities (ion pairs per unit volume). It may be noted that the response drops to nearly one-third as the source strength increases from $243.5 \mathrm{~Bq}$ to $17490 \mathrm{~Bq}$.

From Table 1 it can be seen that the response is a function of the MPV and the distance of the source from the detector. The time required for measurement of pipe contamination can be calculated. Assume an error of $1 \mathrm{~V}$ each in the measurement of the initial and final voltage. Thus, total voltage measurement uncertainty is $\sqrt{2}$. Assume a measurement produces a drop of $15 \mathrm{~V}$, which means a voltage measurement uncertainty of $\sqrt{ } 2 \times 100 / 15$ or approximately $10 \%$. Taking an average response (for the 3.05-m-long pipe) of about $0.15 \mathrm{mV}$ disintegration ${ }^{-1}$, (corresponding

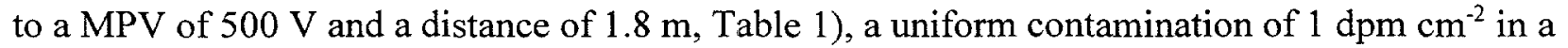
$152-\mathrm{mm}$ pipe, as shown below, can be measured in about 7 minutes.

Surface area of $3.3 \mathrm{~m}$ pipe

Total activity in pipe

This activity will result in an electret voltage drop

Time required for $15 \mathrm{~V}$ drop

$$
\begin{aligned}
& =\pi(15.2) 305 \mathrm{~cm}^{2}=14564 \mathrm{~cm}^{2} \\
& =1 \mathrm{dpm} \mathrm{cm} \mathrm{cm}^{-2} \times 14564 \mathrm{~cm}^{2}=14564 \text { disintegration minute }{ }^{-1} \\
& =0.15 \mathrm{mV} \text { disintegration }{ }^{-1} \times 14564 \text { disintegration minute }^{-1} \\
& =2.18 \mathrm{~V} \text { minute }^{-1} \\
& =15 \mathrm{~V} /\left(2.18 \mathrm{~V} \text { minute }{ }^{-1}\right) \\
& =6.9 \mathrm{~min}
\end{aligned}
$$




\section{Coaxial system}

In the four-hole system the air carrying the ions exits the system through four holes. There is a competition between ions collected by the electrostatic field due to charge on electret and those escaping the system due to flow field. The ion collection can be improved if this flow velocity is reduced without compromising total flow rate in the pipe. This can be achieved by increasing the area of the opening for the air exhaust. Inner diameter of the inner pipe for the 152-mm diameter pipe test in the coaxial system is $53.5 \mathrm{~mm}$. The area of cross-section in this pipe is nearly 4.4 times the area of the four 12.7-mm diameter holes of the four-hole system. Thus, for a given total flow, velocity of the air through inner pipe of the coaxial system will be nearly a quarter of that through holes in the four-hole system. For a 304-mm test pipe, velocity through the inner pipe of $21.8 \mathrm{~mm}$ diameter will be significantly lower.

Using this system, measurements were performed for 152-mm and 30.4-mm diameter pipes.

\section{2-mm pipe}

For this pipe measurements were performed at two flow velocities of air at various source-pipeend distances. Table 2 and Table 3 give the response of the EIC at flow velocities (through inner pipe) of $95 \mathrm{~cm} \mathrm{~s}^{-1}$ and $395 \mathrm{~cm} \mathrm{~s}^{-1}$, respectively. The corresponding flow velocities through the annular space between the pipes are $13.9 \mathrm{~cm} \mathrm{~s}^{-1}$ and $57.8 \mathrm{~cm} \mathrm{~s}^{-1}$. It can be seen from these tables that at low velocities, response decreases as the distance from the detector increases. It is due to greater time spent by the ions in the pipe before their transport to the detector. Loss of the ions due to recombination increases as the ions spend more time in the atmosphere of ions of opposite polarity.

At high flow velocities the residence time in the pipe is smaller by a factor of four. The response remains practically the same at all distances. The enhanced response at $3.08 \mathrm{~m}$ can not be easily explained. The repeated experiments gave similar results. It may also be noted that the response at higher velocity is lower than that at lower velocity. It is due to an increased velocity flow field competing with the electrostatic field due to voltage on the electret, which is responsible for ion collection.

Overall this pipe system shows practically the same response (Table 2) as a four-hole system. With this pipe system also a uniform alpha contamination of $1 \mathrm{dpm} \mathrm{cm}$ in the pipe can be measured in about 7 minutes. At higher velocity through the pipe, the time required for the measurement of the same contamination will be nearly 14 minutes.

Table 4 gives the response of the EIC for alpha sources of different strengths placed at a fixed distance from the pipe-end. It can be seen that the response decreases by a factor of nearly 10 as the source strength increases from $243.5 \mathrm{~Bq}$ to 17490 . In may be noted that this decrease is higher than that for the four-hole system. In the coaxial system the flow velocity is lower (13.9 $\left.\mathrm{cms}^{-1}\right)$ than in the four-hole system $\left(18.6 \mathrm{cms}^{-1}\right)$. Further, although the distance of the sources from the test pipe-end was the same $(0.76 \mathrm{~m})$ in both systems, the length of the chamber holding the electret was larger in the coaxial system $(80 \mathrm{~mm})$ than in the four-hole system $(50 \mathrm{~mm})$. Thus, ions spent a longer time in the vicinity of ions of opposite polarity in the coaxial pipe system than in the four-hole system, resulting in increased loss of ions due to recombination in the coaxial system. 


\section{4-mm pipe}

Tables 5 and 6 show the response of 304-mm diameter pipe (inner pipe: inner diameter $204 \mathrm{~mm}$, outer diameter $218 \mathrm{~mm}$ ) at various distances at two flow velocities of $23.3 \mathrm{~cm} \mathrm{~s}^{-1}$ and $43.8 \mathrm{~cm} \mathrm{~s}^{-1}$ in the annular space. At high velocity the response remains practically the same at all positions of the source inside the pipe. At small velocities too the response is constant as long as the source is within $2.3 \mathrm{~m}$ from the detector-end of the pipe. At higher distances the response decreases. This may be due to the flow configuration. It may be noted that the air enters the annular space between the pipes at one end, which is approximately $6.4 \mathrm{~m}$ from the detector-end of the pipe. At low velocity (Reynold number $\sim 1330$ ) the air flow may not be fully developed by the time the air travels a distance of $4.1 \mathrm{~m}$ ( $2.3 \mathrm{~m}$ from the detector-end of pipe). It may not be picking up ions from the entire segment (that falls within the range of alpha particles) of the annular space between the pipes. Hence, fewer ions may be transported toward the detector. At high velocity (Reynold number $\sim 2500$ ) due to near turbulent flow the air flow might be developed in a shorter distance.

A uniform alpha contamination of $1 \mathrm{dpm} \mathrm{cm}$ in this pipe can be measured in about 4 minutes.

\section{CONCLUSIONS}

Electret ion chamber technology in combination with ion transport technology can be used for measurement of alpha contamination inside pipes of large-bore diameters. An alpha contamination at the level of free release can be measured in less than 10 minutes using a shorttime (ST) electret. Measurement times can be further reduced to one-half using sensitive electrets. The time needed for measurement of contamination depends on a number of factors, such as dimensions of the pipe, location of contamination, flow conditions, contamination level, measurement system design, and location of the EIC from the pipe. A systematic study of these parameters is very important for the design of a system for alpha contamination measurement inside the pipes.

\section{RECOMMENDATIONS}

Measurement of alpha contamination inside pipes using direct methods is a difficult task. The present study has demonstrated that a combination of ion transport and electret ion chamber technologies can be used for such measurements. It is important that a systematic study of various parameters be carried out to develop a system based on sound fluid dynamic and radiological aspects. It is also important to compare the performance of such a system with that of a gamma spectroscopic system, measuring low abundance X-rays emitted by alpha emitters, which is being designed by Canberra. 


\section{REFERENCES}

Dua, S. K., Biswas, S. K., Szerszen, P., Boudreaux, J., and Ebadian, M. A., 1997, "Measurement of alpha contamination inside pipes using electret ion chambers," Proceedings Xchange'97 The Global D\&D Marketplace, pp. 3-246 to 3-253. Hemispheric Center for Environmental Technology, Florida International University, 10555 W. Flagler Street, Miami, Florida, December 1-5.

Dua, S. K., Biswas, S. K., Szerszen, P., Boudreaux, J., and Ebadian, M. A., 1998, "Measurement of Surface Alpha Contamination using Electret Ion Chambers", submitted In press, Health Physics.

Kendrick, D. T., and Cremer, C. D., 1996, "Pipe Explorer: Overview, Applications, and Recent Developments," Spectrum '96, International Topical Meeting on Nuclear and Hazardous Waste Management, Seattle, WA, August 18-23.

Kenper, K., 1998, "Long-Range Alpha Detection," Health Physics, Vol. 75, pp. 572-573.

Knoll, Glenn F., 1989, "Ionization Chambers" in Radiation Detection and Measurement, $2^{\text {nd }}$ Edition, Wiley, New York, p.134.

Kotrappa, P., Dempsey, J. C., Stieff, L. R., and Brubaker, T. 1992, "Electret Ion Chamber System for Measurement of Environmental Radon and Gamma Radiation," Radiation Protection Dosimetry, Vol.45, pp. 107-110.

Kotrappa, P., and Stieff, L. R., 1997, "Ion Transfer Electret Ion Chamber to Measure Alpha Surface Contamination inside Pipes," $42^{\text {nd }}$ Annual Meeting of the Health Physics Society, San Antonio, TX, June 29- July 3.

Meyer, K. E., Gammage, R. B., Dudney, C. S., Reed-Walker, S., Kotrappa, P., Wheeler, R. V., and Salasky, M., 1994, "Field Measurements Of Plutonium And Americium In Soils At The Nevada Test Site Using Passive Alpha Detectors," Radioactivity And Radiochemistry Vol. 5, pp. 26-41.

Meyer, K. E., Gammage, R. B., Dudney, C. S., and Kotrappa, P., 1995, "In-Situ Screening for Gross Alpha Activity in Soils using Electret Ion Chambers," DOE Methods for Evaluating Environmental and Waste Management Samples, Steve Goheen, ed., Batelle Pacific Northwest Laboratories, DOE/EM-0089T.

Rawool-Sullivan, M. W., and Vaccarella, J., 1994, "The Application of Ion Transport Technology for Measuring Contamination within Glove Boxes," Los Alamos National Laboratory Document, LA-UR-94-3707, Los Alamos Laboratory, Los Alamos, New Mexico 87545.

Rawool-Sullivan, M. W., Conaway, J. G., MacArthur, D. W., and Vaccarella, J., 1996, "Alpha Contamination Assessment for D\&D Activities: Monitoring Pipe Interiors," Los Alamos National Laboratory Document, LA-13063-MS, UC-940, Los Alamos Laboratory, Los Alamos, New Mexico 87545. 
Ion Vew
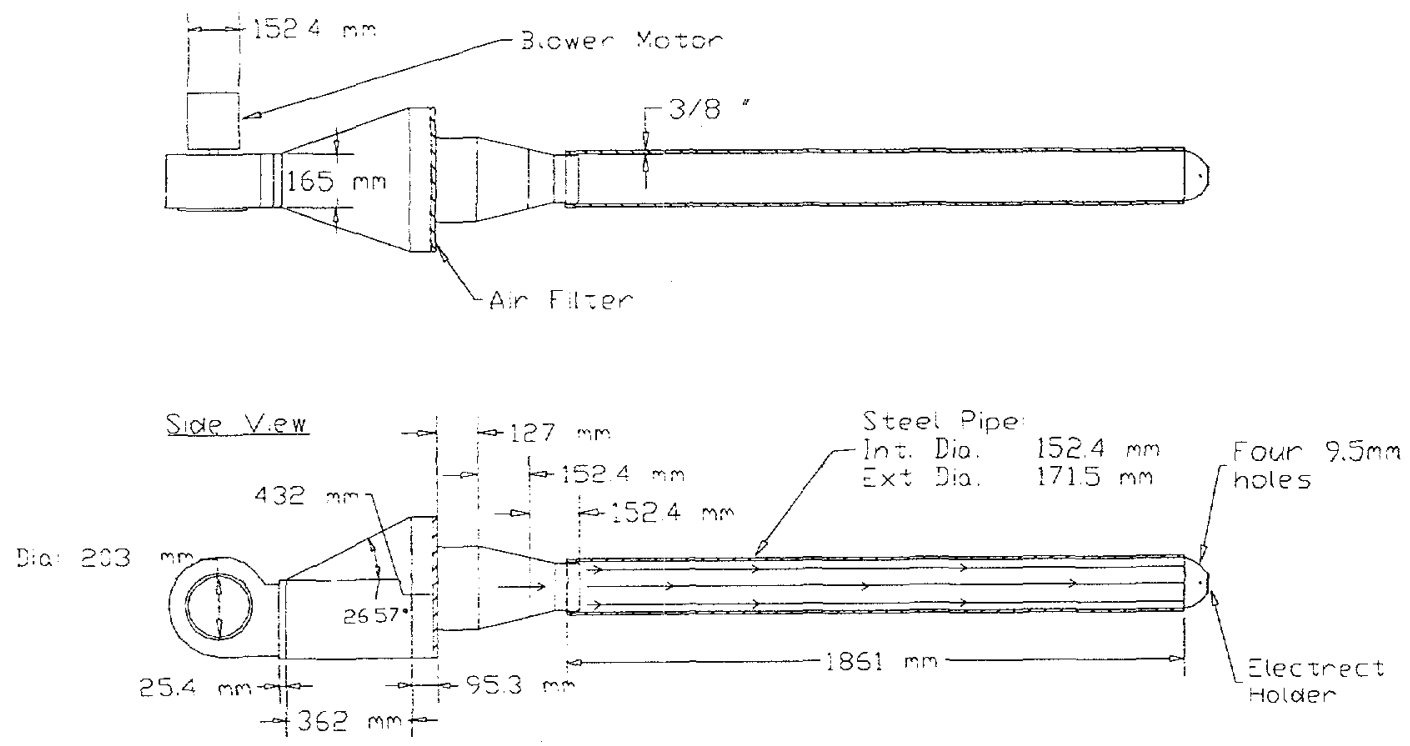

Figure 1. Experimental setup for pipe characterization showing blower, pipe, and electret ionization chamber.

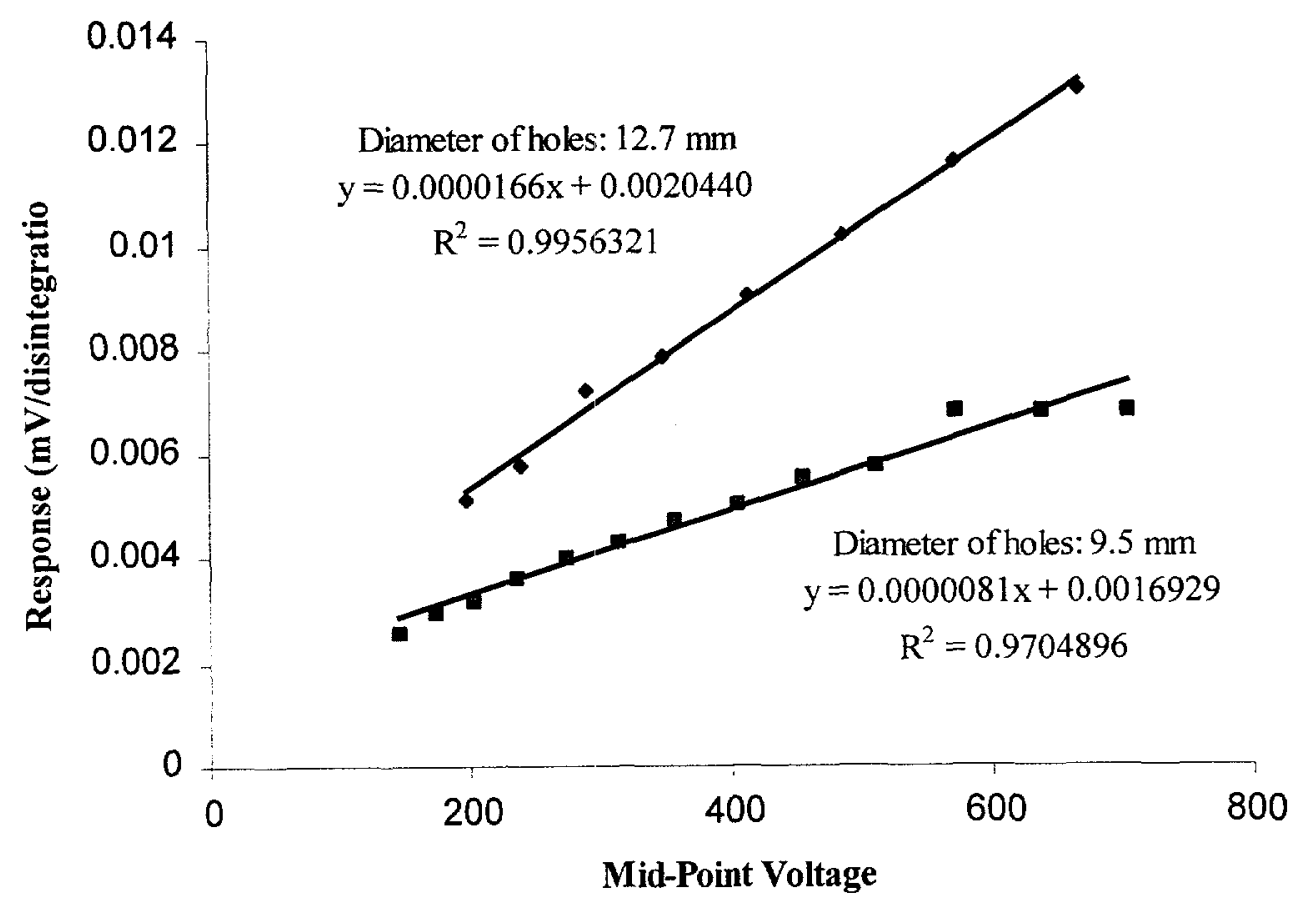

Figure 3. Response of an ST electret for $12.7-\mathrm{mm}$ and $9.5-\mathrm{mm}$ diameter holes in four-hole system; source-pipe end distance: $0.76 \mathrm{~m}$. 


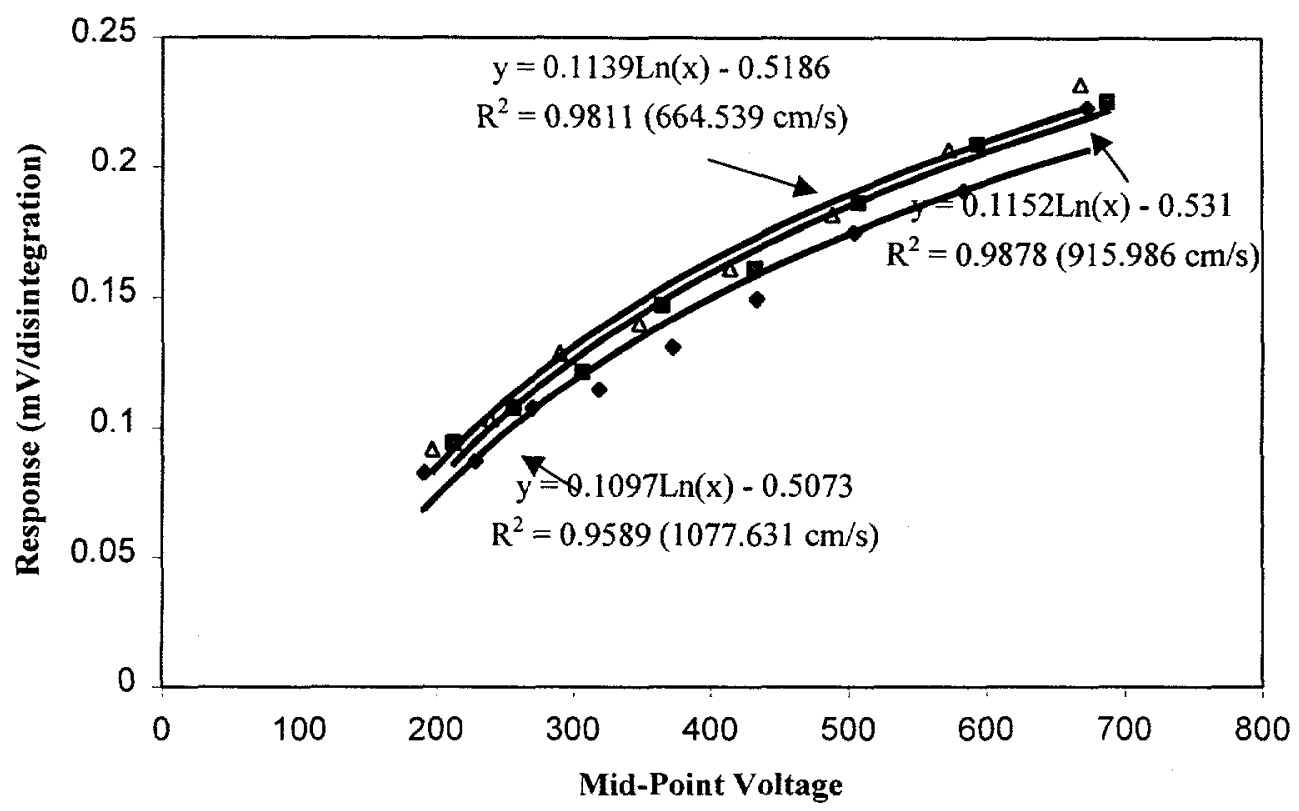

Figure 4. Response of an ST Electret for $3625 \mathrm{~Bq}^{-241} \mathrm{Am}$ source placed at 762 $\mathrm{mm}$ from the detector end of 152-mm diameter pipe at different air flow velocities through four $12.7-\mathrm{mm}$ diameter holes.

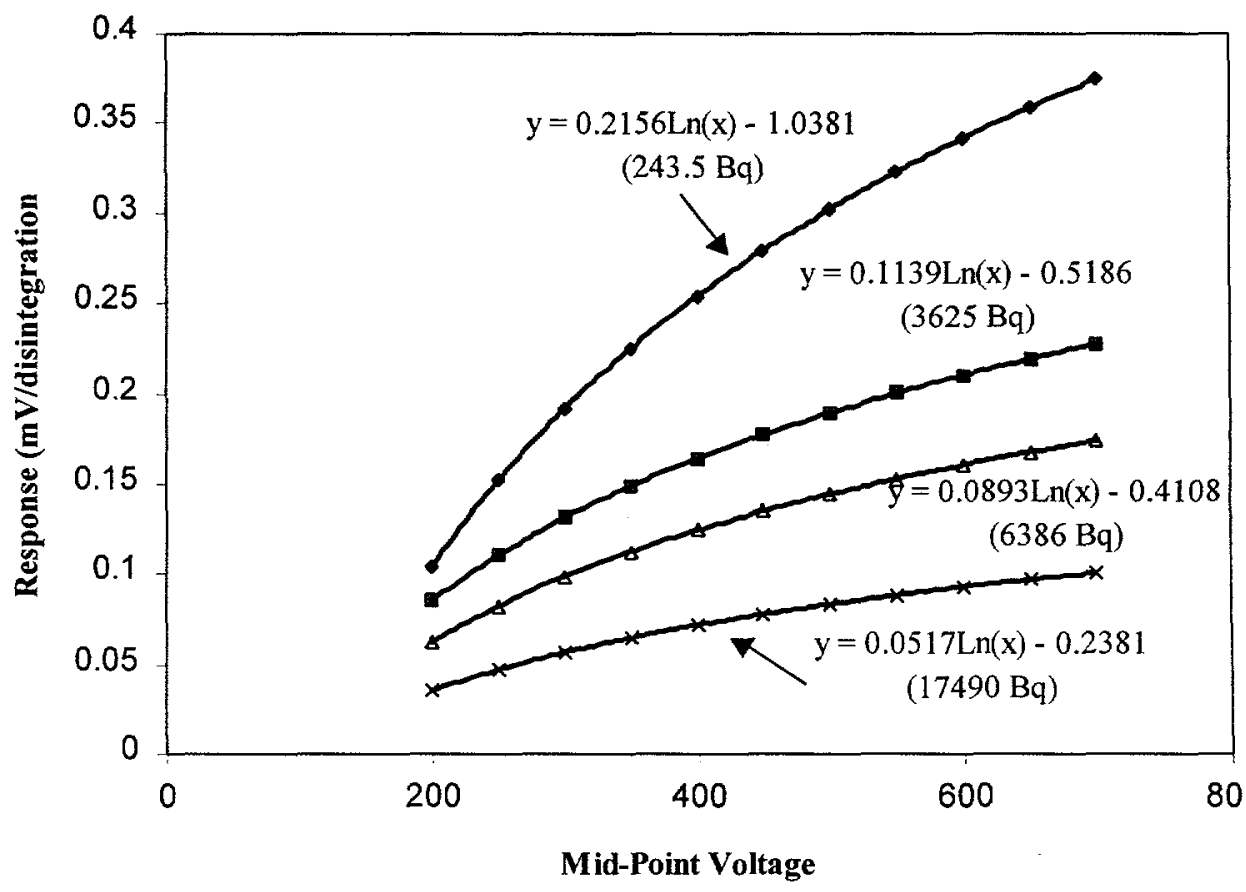

Figure 5. Response of an ST electret for ${ }^{-241} \mathrm{Am}$ sources of different strengths placed at $762 \mathrm{~mm}$ from the detector end of 152- $\mathrm{mm}$ diameter pipe at air flow velocity of $664.53 \mathrm{~cm} \mathrm{~s}^{-1}$ through four $12.7-\mathrm{mm}$ diameter holes. 
Table 1.

Response of an ST electret for $3625 \mathrm{~Bq}^{-241} \mathrm{Am}$ source at different distances from the detector end of 152- $\mathrm{mm}$ diameter pipe at a velocity of $664.53 \mathrm{~cm} \mathrm{~s}^{-1}$ through four $12.7-\mathrm{mm}$ diameter holes.

\begin{tabular}{|c|c|c|c|c|c|c|c|}
\hline \multirow{3}{*}{$\begin{array}{c}\text { MPV } \\
\text { (volts) }\end{array}$} & \multicolumn{7}{|c|}{ Responses (mV/disintegration) } \\
\cline { 2 - 8 } & \multicolumn{7}{|c|}{ Source-pipe end distance (mm) } \\
\cline { 2 - 8 } & 25.4 & 152.4 & 304.8 & 762 & 1524 & 2286 & 2921 \\
\hline 700 & 0.3246 & 0.3489 & 0.2278 & 0.2276 & 0.1892 & 0.1247 & 0.0651 \\
\hline 650 & 0.3101 & 0.3390 & 0.2193 & 0.2191 & 0.1816 & 0.1210 & 0.0625 \\
\hline 600 & 0.2944 & 0.3284 & 0.2101 & 0.2100 & 0.1735 & 0.1170 & 0.0597 \\
\hline 550 & 0.2774 & 0.3167 & 0.2001 & 0.2001 & 0.1646 & 0.1127 & 0.0567 \\
\hline 500 & 0.2587 & 0.3040 & 0.1892 & 0.1892 & 0.1548 & 0.1080 & 0.0534 \\
\hline 450 & 0.2381 & 0.2900 & 0.1771 & 0.1772 & 0.1441 & 0.1028 & 0.0498 \\
\hline 400 & 0.2150 & 0.2743 & 0.1635 & 0.1638 & 0.1320 & 0.0970 & 0.0457 \\
\hline 350 & 0.1889 & 0.2564 & 0.1482 & 0.1486 & 0.1184 & 0.0904 & 0.0411 \\
\hline 300 & 0.1587 & 0.2359 & 0.1305 & 0.1311 & 0.1026 & 0.0827 & 0.0358 \\
\hline 250 & 0.1230 & 0.2116 & 0.1095 & 0.1103 & 0.0840 & 0.0737 & 0.0294 \\
\hline 200 & 0.0793 & 0.1818 & 0.0839 & 0.0849 & 0.0612 & 0.0627 & 0.0217 \\
\hline
\end{tabular}

Table 2.

Response of an ST electret for a $398.3 \mathrm{~Bq}$ source ${ }^{-239}$ Puplaced at different distances from the detector end of a coaxial 152-mm diameter pipe at air flow velocity of $13.9 \mathrm{cms}^{-1}$.

\begin{tabular}{|c|c|c|c|c|c|}
\hline \multirow{2}{*}{$\begin{array}{c}\text { MPV } \\
\text { (volts) }\end{array}$} & \multicolumn{5}{|c|}{ Response (mV/disintegration) } \\
\cline { 2 - 6 } & \multicolumn{5}{|c|}{ Source-pipe end distance (mm) } \\
\cline { 2 - 6 } & 279.4 & 762 & 1524 & 2286 & 3048 \\
\hline 700 & 0.4573 & 0.3492 & 0.2072 & 0.1746 & 0.0926 \\
\hline 650 & 0.4362 & 0.3332 & 0.1969 & 0.1640 & 0.0867 \\
\hline 600 & 0.4133 & 0.3158 & 0.1858 & 0.1525 & 0.0804 \\
\hline 550 & 0.3885 & 0.2969 & 0.1737 & 0.1401 & 0.0736 \\
\hline 500 & 0.3613 & 0.2762 & 0.1605 & 0.1264 & 0.0660 \\
\hline 450 & 0.3312 & 0.2533 & 0.1459 & 0.1113 & 0.0577 \\
\hline 400 & 0.2976 & 0.2277 & 0.1295 & 0.0945 & 0.0484 \\
\hline 350 & 0.2594 & 0.1988 & 0.1110 & 0.0754 & 0.0379 \\
\hline 300 & 0.2154 & 0.1653 & 0.0896 & 0.0533 & 0.0257 \\
\hline 250 & 0.1634 & 0.1257 & 0.0643 & 0.0272 & 0.0113 \\
\hline 200 & 0.0997 & 0.0773 & 0.0333 & & \\
\hline
\end{tabular}


Table 3.

Response of an ST electret for a $243.5 \mathrm{~Bq}^{241} \mathrm{Am}$ source placed at different distances from the detector end of a coaxial 152-mm diameter pipe at air flow velocity of $57.8 \mathrm{cms}^{-1}$

\begin{tabular}{|c|c|c|c|c|c|}
\hline \multirow{3}{*}{$\begin{array}{l}\text { MPV } \\
\text { (volts) }\end{array}$} & \multicolumn{5}{|c|}{ Response (mV/disintegration) } \\
\hline & \multicolumn{5}{|c|}{ Source-pipe end distance ( $\mathrm{mm})$} \\
\hline & 762 & 762 & 1524 & 2286 & 3048 \\
\hline 700 & 0.0821 & 0.0829 & 0.0907 & 0.0906 & 0.1205 \\
\hline 650 & 0.0778 & 0.0786 & 0.0863 & 0.0868 & 0.1159 \\
\hline 600 & 0.0733 & 0.0740 & 0.0816 & 0.0828 & 0.1109 \\
\hline 550 & 0.0683 & 0.0689 & 0.0765 & 0.0783 & 0.1055 \\
\hline 500 & 0.0629 & 0.0634 & 0.0709 & 0.0735 & 0.0996 \\
\hline 450 & 0.0569 & 0.0572 & 0.0646 & 0.0681 & 0.0931 \\
\hline 400 & 0.0502 & 0.0504 & 0.0577 & 0.0622 & 0.0858 \\
\hline 350 & 0.0426 & 0.0426 & 0.0498 & 0.0554 & 0.0775 \\
\hline 300 & 0.0338 & 0.0337 & 0.0407 & 0.0476 & 0.0679 \\
\hline 250 & 0.0235 & 0.0231 & 0.0300 & 0.0383 & 0.0566 \\
\hline 200 & 0.0108 & 0.0101 & 0.0168 & 0.0270 & 0.0428 \\
\hline
\end{tabular}

Table 4.

Response of an ST electret for ${ }^{-241}$ Amsources of different strengths placed at $762 \mathrm{~mm}$ from the detector end of a 152-mm coaxial pipe at air flow velocityof $13.9 \mathrm{cms}^{-1}$

\begin{tabular}{|c|c|c|c|c|}
\hline \multirow{3}{*}{$\begin{array}{c}\text { MPV } \\
\text { (volts) }\end{array}$} & \multicolumn{4}{|c|}{ Response (mV/disintegration) } \\
\cline { 2 - 5 } & \multicolumn{4}{|c|}{ Source strength (Bq) } \\
\cline { 2 - 5 } & 243.5 & 3625 & 6386 & 17490 \\
\hline 700 & 0.3957 & 0.1233 & 0.0895 & 0.0355 \\
\hline 650 & 0.3739 & 0.1168 & 0.0852 & 0.0336 \\
\hline 600 & 0.3504 & 0.1097 & 0.0807 & 0.0315 \\
\hline 550 & 0.3247 & 0.1020 & 0.0757 & 0.0293 \\
\hline 500 & 0.2967 & 0.0935 & 0.0703 & 0.0268 \\
\hline 450 & 0.2657 & 0.0842 & 0.0643 & 0.0240 \\
\hline 400 & 0.2310 & 0.0737 & 0.0576 & 0.0210 \\
\hline 350 & 0.1917 & 0.0619 & 0.0500 & 0.0175 \\
\hline 300 & 0.1463 & 0.0483 & 0.0412 & 0.0135 \\
\hline 250 & 0.0926 & 0.0321 & 0.0309 & 0.0088 \\
\hline 200 & 0.0269 & 0.0123 & 0.0182 & 0.0030 \\
\hline
\end{tabular}


Table 5.

Response of an ST electret for a $243.5 \mathrm{~Bq}^{-241}$ Amsource placed at different distances from the detector end of a coaxial 304-mm diameter pipe at air flow velocity of $23.3 \mathrm{cms}^{-1}$

\begin{tabular}{|c|c|c|c|c|c|c|c|}
\hline \multirow{2}{*}{$\begin{array}{c}\text { MPV } \\
\text { (volts) }\end{array}$} & \multicolumn{7}{|c|}{ Response (mV/disintegration) } \\
\cline { 2 - 8 } & \multicolumn{7}{|c|}{ Source-pipe end distance (mm) } \\
\cline { 2 - 8 } & 152.4 & 762 & 1905 & 2286 & 2667 & 2997.2 & 3048 \\
\hline 700 & 0.1755 & 0.2007 & 0.1647 & 0.1657 & 0.0865 & 0.0698 & 0.0666 \\
\hline 650 & 0.1694 & 0.1871 & 0.1604 & 0.1609 & 0.0838 & 0.0655 & 0.0607 \\
\hline 600 & 0.1628 & 0.1734 & 0.1558 & 0.1558 & 0.0808 & 0.0608 & 0.0552 \\
\hline 550 & 0.1556 & 0.1597 & 0.1507 & 0.1502 & 0.0776 & 0.0558 & 0.0501 \\
\hline 500 & 0.1477 & 0.1459 & 0.1452 & 0.1441 & 0.0742 & 0.0502 & 0.0454 \\
\hline 450 & 0.1389 & 0.1320 & 0.1390 & 0.1374 & 0.0703 & 0.0441 & 0.0411 \\
\hline 400 & 0.1292 & 0.1180 & 0.1322 & 0.1299 & 0.0660 & 0.0372 & 0.0372 \\
\hline 350 & 0.1181 & 0.1040 & 0.1244 & 0.1213 & 0.0611 & 0.0294 & 0.0337 \\
\hline 300 & 0.1054 & 0.0898 & 0.1155 & 0.1114 & 0.0555 & 0.0204 & 0.0306 \\
\hline 250 & 0.0903 & 0.0755 & 0.1049 & 0.0998 & 0.0488 & 0.0098 & 0.0279 \\
\hline 200 & 0.0718 & 0.0611 & 0.0919 & 0.0855 & 0.0406 & & 0.0256 \\
\hline
\end{tabular}

Table 6.

Response of an ST electret for a 243.5 $\mathrm{Bq}^{-241}$ Amsource placed at different distances from the detector end of a coaxial 304-mm diameter pipe at air flow velocity of $43.8 \mathrm{cms}^{-1}$

\begin{tabular}{|c|c|c|c|c|c|c|}
\hline \multirow{3}{*}{$\begin{array}{c}\text { MPV } \\
\text { (volts) }\end{array}$} & \multicolumn{6}{|c|}{ Response (mV/disintegration) } \\
\cline { 2 - 7 } & \multicolumn{6}{|c|}{ Source-pipe end distance (mm) } \\
\cline { 2 - 7 } & 76.2 & 152.4 & 304.8 & 762 & 1524 & 3048 \\
\hline 700 & 0.1727 & 0.2422 & 0.1714 & 0.1637 & 0.1713 & 0.1514 \\
\hline 650 & 0.1634 & 0.2275 & 0.1629 & 0.1622 & 0.1676 & 0.1451 \\
\hline 600 & 0.1538 & 0.2129 & 0.1540 & 0.1591 & 0.1626 & 0.1380 \\
\hline 550 & 0.1437 & 0.1985 & 0.1446 & 0.1544 & 0.1562 & 0.1301 \\
\hline 500 & 0.1332 & 0.1841 & 0.1349 & 0.1480 & 0.1486 & 0.1214 \\
\hline 450 & 0.1223 & 0.1699 & 0.1248 & 0.1401 & 0.1396 & 0.1118 \\
\hline 400 & 0.1110 & 0.1558 & 0.1143 & 0.1306 & 0.1292 & 0.1014 \\
\hline 350 & 0.0993 & 0.1418 & 0.1034 & 0.1195 & 0.1176 & 0.0901 \\
\hline 300 & 0.0871 & 0.1279 & 0.0921 & 0.1068 & 0.1046 & 0.0780 \\
\hline 250 & 0.0745 & 0.1141 & 0.0804 & 0.0925 & 0.0903 & 0.0651 \\
\hline 200 & 0.0615 & 0.1005 & 0.0683 & 0.0766 & 0.0747 & 0.0514 \\
\hline
\end{tabular}

